\title{
A systematic review of sports sponsorship for public health and social marketing
}

\section{Background}

Sports sponsorship has been a key health promotion strategy that has been used over the last thirty years, yet academic literature on the value of sponsorship for social marketing and public health is limited. An assessment of the value of sponsorship assists to establish the factors that should be considered by social marketers and public health practitioners when implementing sponsorship. Drawing from commercial marketing literature sponsorship has been described by authors such as Meenaghan $(1983$, p.9) as 'the provision of assistance either financial or in-kind to an activity by a commercial organization for the purpose of achieving commercial objectives'. However, in social marketing and public health, where sponsorship is frequently used to achieve social rather than commercial objectives, studies (see for example Madill and O'Reilly, 2010; Madill et al., 2014; O’Reilly and Madill, 2007) have relied on Rifon et al.'s (2004, p.30) definition which adopts a wider stance indicating the purpose of sponsorship as an exchange process in which a 'corporation [or other investor, for example a health promotion foundation] creates a link with an outside issue or event, hoping to influence the audience by the connection' which in turn may assist to deliver sustained social programs. Taken together, definitions indicate that sponsorship in public health and social marketing may involve the provision of assistance either financial or in-kind and/or the formation of a partnership and a resulting exchange that mutually benefits both parties. Sponsorship arrangements involve two parties: a sponsor and a sponsee. The sponsor is responsible for providing cash and/or an in-kind contribution (for example products such as athletic apparel or services) to a sponsee in exchange for promotional opportunities to create links with an event, cause, or organization (Madill and O'Reilly, 2010; O'Reilly and Madill, 2007). In social marketing and public health sponsors are usually private companies (Rodgers 
and Bae, 2007), and sponsees are frequently sporting and arts non-for-profit and government organisations, teams, programmes, persons and events. Sponsees rely on achieving their goals via resources provided by sponsors (Rosenberg and Ferguson, 2014). Partnering with a commercial organisation can assist behaviour change practitioners, who typically have limited budgets, to reach a larger audience. Further, private partnerships can help behaviour change practitioners to deliver more value to the target audience. For example, private partnerships can deliver discount offers that attract attention or repeat engagement with a campaign which in turn reinforces the campaign aims for the target audience and increases likelihood of delivering the desired change.

Sport is an important context for public health organisations as it offers potential to deliver public health messages to large populations (Corti et al., 1997a). Further, according to a National Health and Medical Research Council review (NHMRC, 1996), strategically targeted sponsorship not only offers a potential for public health and social marketing campaigns to reach priority groups, but also facilitates structural (i.e. environmental) changes in sporting venues (Crisp and Swerissen, 2003). Some of the first examples of health sponsorship of sports emerged in the 1980s in the United Kingdom (Hastings et al., 1988), followed by the United States (Olsen, 1999). In the 1990s, health sponsorship became commonly used in Australia (Giles-Corti et al., 2001). More recently, Australian health promotion foundations have been considered as leaders in using sponsorship as a health promotion strategy (Corti et al., 1997a). The rise of health sponsorship in Australia can be by and large attributed to the creation of health promotion foundations, aiming initially to compete with tobacco sponsorship (Jalleh et al., 2002). Health sponsorship was first used to financially support sports and arts organizations that had historically relied on tobacco industry sponsorship for their survival. Health sponsorship has been identified by some authors as a uniquely Australian phenomenon, where health promotion foundations act as 
sponsors (Madill and O'Reilly, 2010), providing for example funds to sports and arts organizations in exchange for health promotion, behavioural change outcomes or assets that include (but are not limited to) naming rights for sporting and cultural events, wearing promotional clothing, and programme advertisements and signage (Crisp and Sverissen, 2003). In other countries, for example in Canada and the United States, where statutory frameworks do not offer the same opportunities to public health bodies, private companies, with their commercial rather than public health objectives, dominate the sports sponsorship landscape in public health (Madill and O'Reilly, 2010). The understanding of health sponsorship as a uniquely Australian public health strategy explains limited availability of relevant literature internationally, and where it does exist it is often not empirically evaluated (ibid.). Therefore this article responds to this gap and aims to provide a systematic review of evaluations of public health and social marketing campaigns reporting the use of sports sponsorship.

\section{Methods}

Following the systematic literature review procedures outlined in Carins and Rundle-Thiele (2014), two searches were conducted to identify public health and social marketing studies reporting the use of sports sponsorship published in peer-reviewed journals. Seven databases (see Table 1) were searched using the following terms: sponsorship* or partnership* AND "social marketing" (Search 1); and sponsorship* AND "public health" AND sport* (Search 2). The use of * allows for singular or plural word forms to be identified. Database names and the number of records retrieved from each database are shown in Table 1. 
The variation in the number of records retrieved from the different databases is explained by the size and the subject specialisation of each database. ProQuest, for example, is made up of 20 databases representing a much larger database than most.

The search processes can be found in Figure 1. The initial results were limited to peerreviewed academic journal articles published up to December 2015 (Search 1) and February 2016 (Search 2). All records retrieved from the seven databases were downloaded to EndNote, the results were collated and duplicate records identified via different databases were removed. The combined total of records downloaded from all databases was 877 in Search 1 and 190 in Search 2. From the initial records collected, 299 (Search 1) and 61 (Search 2) duplicate records were removed, leaving 578 unique sources in Search 1 and 129 unique sources in Search 2. The remaining sources were then screened based upon their title and abstract. To ensure that records were an accurate representation of the use of sports sponsorship for social marketing and public health, the following exclusion criteria were applied to exclude records that did not report evaluations of public health and social marketing campaigns using sports sponsorship: records not including sports sponsorship (e.g. when other forms of sponsorship, for example arts sponsorship, were the main focus), records that did not state the use of social marketing (Search 1), records not including public health campaigns (Search 2), reviews or conceptual papers, records detailing formative research with no sponsorship executed, records containing only references to dissertations, abstracts, conference papers and book chapters, and records not in English (see Figure 1).

A large number of records (510 in Search 1 and 118 in Search 2) were removed once the exclusion criteria were applied, leaving respectively 68 and 11 unique studies. Backward searching was completed by examining the reference lists of all 79 journal articles for further 
sources that may give additional information regarding sports sponsorship that may fit the search criteria. The identified sources were located and examined in the same way as the original records, through title and abstract analysis. Forward searching was conducted using author and campaign names to search within Google Scholar and the University library databases to locate additional academic papers related to specific campaigns as well as additional campaigns undertaken by the authors.

The backward and forward searching yielded 65 additional academic papers, giving a total of 144 studies. Full texts of all studies were downloaded to EndNote and content analysed to identify relevance to sports sponsorship and the review aims. The overwhelming majority of studies included only very brief references to sports sponsorship, for example a sentence stating the use of sports sponsorship as part of a wider social marketing campaign without providing any details of the sponsorship or its evaluation. Following the analysis of all studies, 17 studies including evaluations of sports sponsorship were included in the final review.

\section{Results}

In total, 17 studies were identified. Drawing on key elements identified in Kubacki et al. (2015) study elements are presented in Table 2. Original names for identified campaigns are shown in italics. The following discussion focuses on budgets, locations, target audiences, aims, evaluation methods and outcomes for each sponsorship programme, i.e. both VicHealth sponsorship programmes and Healthway, and the remaining individual studies. Four of the studies were reviewed as individual sponsorship campaigns (Corti et al., 1997; Dobbinson et al., 1999; Jalleh et al., 2001; Jalleh et al., 2002) - although they were associated with Healthway and VicHealth sponsorship programmes the evaluations reported in those studies 
focused on specific campaigns rather than evaluations of the Healthway and VicHealth sponsorship programmes (see Table 2).

Insert Table 2 About Here

\section{Locations and budgets}

All studies included in this review were found to be in developed and English speaking countries; fifteen studies were conducted in Australia. The majority of them focused on evaluations of two significant health sponsorship programmes run by two state health promotion agencies - Western Australia's Healthway (8 studies) and Victoria's VicHealth (2 studies). Four studies reported specific campaigns associated with the VicHealth sponsorship programme (Dobbinson et al., 1999) and Healthway (Corti et al., 1997; Jalleh et al., 2001; Jalleh et al., 2002). The remaining study in Australia was conducted in the Northern Territory (Ivers et al., 2006). One study was conducted in Scotland (Hastings et al., 1988) and one in the United States (Weinreich et al.1999).

Financial details were not reported in all studies, and when they were it is difficult to make direct comparisons as the years of funding reported spread over nearly thirty years, from 1984 (Hastings et al., 1988) to 2013 (Rosenburg and Ferguson, 2014). This precludes drawing conclusions from this review on the costs of running an effective sponsorship programme. All studies reported state departments of health and their agencies (e.g. The Western Australian Health Promotion Foundation (Healthway) and VicHealth) as sponsors. 


\section{Target audiences}

Target audiences are the group(s) at which the public health and social marketing campaigns are aimed. All studies included in this review fell into one of two broad categories of target audience.

The first group of sponsorships primarily targeted organisations. It included eight Healthway sponsorship programme evaluation studies focused on sport, arts and racing organisations (Corti et al., 1995; Corti et al., 1997a; Donovan et al., 1997; Holman et al., 1996; Holman et al., 1997; Giles-Corti et al., 2001; Oddy et al., 1995; Rosenburg and Ferguson, 2014) and two VicHealth sponsorship program evaluation studies (Crisp and Swerissen, 2003; Dobbinson et al., 2006). In contrast the primary foci of VicHealth's sponsorship were sporting and other organisations promoting healthy environments in the community. Both organisations' sponsorship programmes broadly aimed to reach spectators, participants, visitors and members associated with sponsees.

The second group includes the seven studies describing campaigns with a diverse range of specific target audiences. For example groups targeted for change included 10-44 year old males with an interest in football (primary audience) and their immediate female relatives (secondary audience) (Hastings et al., 1988), blue-collar workers, minority groups and lowincome youth (Weinreich et al., 1999), 8-14 year old children enrolled in holiday football clinics (Corti et al., 1997), lifesavers (Dobbinson et al., 1999), Aboriginal Australians in remote communities (Ivers et al., 2006), junior basketball and rugby union players, parents and coaches (Jalleh et al., 2001), and 18-30 year old males and 18+ smokers (Jalleh et al., 2002). Previous studies contend that sponsorship may be effective at reaching hard-to-reach and hard-to-impact target audiences in the community (e.g. Corti et al., 1995). One may therefore argue that those seven studies reported sponsorship of activities that enabled access to those specific audiences, for example via football games (Hastings et al., 1988), racing 
events (Weinreich et al., 1999), holiday football clinics (Corti et al., 1997), and programmes in Aboriginal communities (Ivers et al., 2006).

\section{Sponsorship aims}

The aims that were reported reflected the multifaceted nature of health sponsorship. Five different types of aims were reported in the studies: aims to change policies, aims to change awareness (including knowledge), behavioural aims, aims to change attitudes, and aims to change social norms. All of the studies analysed in this review stated a specific aim for their sponsorship programme ensuring a focus and goal, and several studies reported more than one aim. Apart from the eight studies evaluating the Healthway sponsorship programme, four other studies identified a combination of two different objectives - awareness and policy (Dobbison et al., 1999), behaviour and policy (Dobbison et al., 2006), attitudes and awareness (Jalleh et al., 2002), and awareness and behaviour (Jalleh et al., 2001).

Policy was the main aim in two large sponsorship programmes provided by Healthway and VicHealth. Eight studies evaluating the Healthway sponsorship programme (Corti et al., 1995; Corti et al., 1997a; Donovan et al., 1997; Holman et al., 1996; Holman et al., 1997; Giles-Corti et al., 2001; Oddy et al., 1995; Rosenburg and Ferguson, 2014) and two studies evaluating different elements of the VicHealth sponsorship programme (Crisp and Swerissen, 2003; Dobbinson et al., 2006) reported policy aims. The main purpose of Healthway's sponsorship programme was to create a healthy environment through structural changes at events, such as introduction of smoke-free policies and provisioning of healthy food choices (Holman et al., 1993). VicHealth's sponsorship programme aimed to implement structural change in sporting settings. 
Awareness was identified as an aim in twelve studies. For example, SunSmart (Dobbison et al., 1999) aimed to educate lifesavers about the need for better sun protection practices to raise awareness of the campaign's message; Smoking? No Way! (Corti et al., 1997) aimed to promote a no smoking message to children, and The Western Australian Mouthguard Promotion Campaign (Jalleh et al., 2001) aimed to increase awareness of the protective benefits of custom-built mouthguards. All eight studies of Healthway sponsorships aimed to fund activities that promote good health (see Table 2).

Four studies reported behavioural aims. For example, Tobacco Action Project aimed to reduce the damaging effects of tobacco for Aboriginal people, consumed as tailor-made cigarettes or 'rollies' of loose tobacco, occasionally smoked in a pipe (commercial, crab-claw or Macassan (Indonesian) pipe) or chewed with eucalyptus ash ('mubbudge') (Ivers et al., 2006), and the Western Australian Mouthguard Promotion Campaign aimed to increase the use of mouthguards among junior players for competition and training (Jalleh et al., 2001).

Three studies reported attitudinal and social norms aims. Attitude is a tendency to evaluate or appraise a behaviour favourably or unfavourably. The sponsorship offered by the Scottish Health Education Group aimed to improve the image of health through the sponsorship link with football, health being defined as fitness, non-smoking and moderation in alcohol consumption (Hastings et al., 1988). Jalleh et al. (2002) aimed to assess the awareness and attitude effects of sponsorships using two campaigns: Respect Yourself and Quit. Social norms were reported as an aim in one study: Tobacco Free Challenge Racing (Weinreich et al., 1999) aimed to change social norms around tobacco among racetrack audiences.

\section{Evaluation methods}

A frequent criticism of social marketing and public health campaigns is the lack of systematic and methodologically sound evaluations (Babor et al., 2010). Best practice campaigns include 
an evaluation component to monitor their effectiveness in the achievement of aims and for identifying areas for increasing the effectiveness of the campaign (Grier and Bryant, 2005).

The overwhelming majority of studies identified in this review (15 out of 17) reported using quantitative surveys as the evaluation method used to research individuals or organisations. For example, in Giles-Corti et al. (2001), 613 randomly selected spectators attending eight Western Australian football league clubs were surveyed to ascertain their support for the introduction of smoke-free policies, and 185 spectators were surveyed following the introduction of a policy banning smoking were conducted to determine awareness of, agreement with, and support for the smoke-free venue policies. In addition, the study reported organisational surveys of all sport, arts, and racing organisations that had commenced Healthway-funded projects during the previous 12 months.

Two studies reported using qualitative interviews. In Tobacco Free Challenge Racing (Weinreich et al., 1999) two series of interviews were conducted with fans and drivers in 1997 and 1998. In Crisp and Swerissen's (2003) study of VicHealth sponsorship programme 33 interviews were conducted with the representatives from 13 sponsored organisations who were responsible for managing the sponsorship within their organisation and relevant staff members from VicHealth and other health agencies.

Two other evaluation methods were reported in the identified studies: sales data (Ivers et al., 2006) and observations (Giles-Corti et al., 2001; Jalleh et al., 2001). In the Tobacco Action Project (Ivers et al., 2006) information on monthly orders for each type of cigarette and tobacco was collected from either the store manager or from the store's wholesaler for each of the communities in the study. Consumption was then calculated using the number of cigarettes or 'cigarette-equivalents' of loose tobacco ordered through stores for each month; this was then divided by the number of community members aged 12 years or older, as estimated from the 1996 Australian Bureau of Statistics Census. One of the Healthway 
evaluation studies (Giles-Corti et al., 2001) reported using observational studies at sporting venues to assess the extent to which smoke-free policies at sporting events were implemented and adhered to. Some 8,212 people were observed adhering to smoke-free policies.

A frequent criticism of research is the lack of matched control groups and the lack of multiple data collection points across time (Babor et al., 2010; Cuijpers, 2002). Five studies reported using both pre and post-tests allowing for comparative data analysis. Tobacco Free Racing Challenge (Weinreich et al., 1999) involved pre- $(\mathrm{n}=339)$ and post-test $(\mathrm{n}=347)$ surveys of racing event attendees. In Smoking? No Way! (Corti et al., 1997) the pre-test questionnaires were administered to children at the beginning of football clinics and prior to the promotional packages being put in place. The post-test questionnaires were administered at the end of the third day of the clinics. All promotional materials used at the clinics were removed before the post-test. Overall, 828 children participated in the pre-test survey and 754 in the post-test. The evaluation of the Western Australian Mouthguard Promotion Campaign employed a quasi-experimental field design with pre- and post-campaign observations (Jalleh et al., 2001). Tobacco Action Project (Ivers et al., 2006) involved pre- and post-evaluation in the intervention communities, at baseline - in the month prior to the planned campaign - and at a follow-up visit, a year later. The evaluation included community-wide surveys to identify any changes in smoking behaviour, attitudes (readiness to quit), and knowledge following the community tobacco campaigns. In Respect Yourself and Quit study (Jalleh et al., 2002) to allow assessment of both awareness and attitude effects without prior questions contaminating later measures, two independent samples were taken pre- and post-test at two events. In addition to those studies two other studies reported multiple data collection points. The Scottish Health Education Group sponsorship (Hastings et al., 1988) of the Scottish FA Cup was monitored in three stages covering the 1984, 1985, and 1986 Scottish Cup competitions. Each year just under 700 men were interviewed face-to-face using a highly 
structured questionnaire. Finally, Giles-Corti et al. (2001) reported conducting organisational surveys in mid-1992 ( $\mathrm{n}=269), 1994(\mathrm{n}=511)$, and $1997(\mathrm{n}=536)$.

Best practice evaluation of social marketing and public health campaigns should also involve the inclusion a control group, to effectively evaluate change in the desired outcome, e.g. behaviour. The use of a control group permits confounding factors to be examined ensuring that a comprehensive understanding of why the change occurs is gained. A control group was established in only two studies. In SunSmart (Dobbison et al., 1999) New South Wales was selected as the control community based on its proximity to Victoria, sufficient beaches frequented by metropolitan beach goers, and limited and relatively recent involvement of lifesavers in sun protective initiatives. In the Western Australian Mouthguard Promotion Campaign Australian Rules Football players were used as a control group (Jalleh et al., 2001).

\section{Outcomes}

As noted earlier social marketing and public health campaigns have a variety of aims including to change behaviours, attitudes, intentions, policy and to raise awareness. Outcome evaluation should ideally be linked to the study aim(s). For example, a study aiming to raise awareness should be evaluating awareness to understand campaign effectiveness. All studies reported some positive outcomes.

\section{Policy}

Policy change outcomes were reported by ten studies. Six of those studies reported positive policy changes associated with the evaluation of Healthway's sponsorship programme. For example, Corti et al. (1995) reported a substantial increase in the level of reform in five of Healthway's priority structural reform areas: provision of smoke-free areas, access for 
disadvantaged groups, safe alcohol practices, healthy food choices and sun protection measures. Two studies also reported policy outcomes associated with VicHealth's sponsorship programme. Crisp and Swerissen (2003) reported that sponsored sporting organisations varied extensively with respect to the extent to which they reported implementing structural changes - while smoke-free venues and sun protection measures were widespread, responsible serving of alcohol and in particular healthy catering options were more difficult to achieve in the sporting context. Dobbinson et al. (2006) reported that the establishment of written policies on the key health areas by sports clubs varied widely by affiliated sport and health area; for example, $70 \%$ of all clubs with bar facilities had written policies on responsible serving of alcohol, but only approximately one-third of sports clubs had a smoke-free policy.

\section{Awareness}

Ten studies showed significant change in awareness. Again, five of them were associated with the evaluation Healthway's sponsorship programme. For example, Holman et al. (1996) and Donovan et al. (1997) reported that $67 \%$ of respondents within the primary target groups were aware of the promoted health message and $60 \%$ could recall the message unprompted. More recently, Rosenberg and Ferguson (2013) reported that awareness of the sponsored health message was 58\% across all sponsored events. In SunSmart (Dobbinson et al., 1999), $29 \%$ of Victoria beach goers were aware of health messages at the beach, and of these $36 \%$ noticed SunSmart. In Tobacco Free Racing Challenge (Weinreich et al., 1999) the results showed continuing increase in awareness, and Hastings et al. (1988) observed that between a quarter and a third of respondents showed prompted awareness of SHEG's involvement with the Scottish Cup, but awareness of both the sponsorship and the advertising fell slightly over the three years.

Attitudes 
A consumer's attitude toward a specific behaviour is a function of how he or she believes that the action will lead to a specific outcome (either favourable or unfavourable). Based on this it may be assumed that attitude change is one of many precursors to behavioural change. However, only three studies reported attitudinal outcomes. Jalleh et al. (2002) reported that the Respect Yourself campaign showed a significant positive change in attitude toward the issue (alcohol moderation). Tobacco Free Racing Challenge (Weinreich et al., 1999) noted a general increase among all respondents in dislike of tobacco sponsorship of racing (34.4\% vs. $40.1 \%)$ and "hating" to sit next to smokers $(41.8 \%$ vs. $53.4 \%)$. In the final study, Hastings et al. (1988) reported that attitudes towards the sponsorship campaign were largely positive and remained stable over time, with only one negative item - "No one notices sponsorship at football matches" - increasing from $29 \%$ to $40 \%$.

\section{Behaviours}

Behavioural outcomes were reported in only three studies, indicating that the evidence that sponsorship can have a direct effect on behaviour remains scarce (Jalleh et al., 2002). A quasi-experimental field design in The Western Australian Mouthguard Promotion Campaign (Jalleh et al., 2001) showed that mouthguard usage increased at competition events among both rugby and basketball players, and at training for basketball players. The SunSmart campaign (Dobbinson et al., 1999) delivered positive behavioural change, with marked improvements in Victorian lifesavers' hat, sunscreen and shade use over the nine years of the campaign. Mixed behavioural outcomes were reported in Tobacco Action Project (Ivers et al., 2006): $10 \%$ of people who claimed to be smokers at the baseline visit had quit at the follow-up survey, however, some ex-smokers and some who reported that they had never smoked took up smoking during the campaign year.

\section{Participation}


Participation in sponsored events was an important measure reported in four Healthway sponsorship programme studies. In Oddy et al. (1995) participation was employed as a measure of whether sponsorships were being allocated to reach appropriate target audiences, with the study reporting that the average Western Australian attended a Healthway-sponsored event on approximately four occasions in 1992. Participation was higher in those who smoked, drank alcohol unsafely, reported sunburn and reported low consumption of fruit and vegetables providing evidence indicating that target audiences had been reached. However, participation was reduced in people who were sedentary. Holman et al. (1996) and Donovan et al. (1997) reported that on average, each Healthway-sponsored project was attended by 94 organisers, elite sports players and arts performers, 1,433 active participants, and 5,923 spectators. Finally Holman et al. (1997) reported that 25 Healthway-sponsored projects reached a total of 1.3 million people, with an average attendance at 50,847 per project.

\section{Other outcomes}

Other outcomes were reported in three of the identified studies. Holman et al. (1996) and Donovan et al. (1997) reported high levels of message acceptance. Of respondents who were aware of the health message, $82 \%$ comprehended the message and, $88 \%$ of these accepted the message. The studies also reported that promotional and educational measures were recorded on 217 projects and one or more promotional benefits were realised in $86 \%$ of projects. Message acceptance was also reported by Rosenberg and Ferguson (2014) stating that acceptance of the sponsored health message was high (91.9\%), with females and respondents over 40 years of age significantly more likely to accept the sponsorship health message compared with males and participants younger than 40 years of age. The authors also reported positive behavioural intentions among $40.6 \%$ of respondents across all sponsorships, with those over the age of 40, 1.7 times more likely to form a relevant behavioural intention compared with people under 40 years of age. 


\section{Discussion}

The aim of this study was to provide a systematic review of evaluations of public health and social marketing campaigns reporting the use of sports sponsorship. This review indicated that in line with an argument made nearly a quarter of a century ago by Holman et al. (1993), academic literature on sports sponsorship practice in public health and social marketing still remains limited. Although much has been written about sponsorship theory (see for example Donovan and Henley, 2010; Madill and O'Reilly, 2010), our review identified only seventeen peer-reviewed studies reporting evaluations of sports sponsorship in social marketing and public health. Further, as the majority of the identified studies were published in the 1990s (largely focusing on the Healthway sponsorship programme), and no studies were published between 2006 and 2014, with only one study published in the last 10 years (Rosenburg and Ferguson, 2014), it is difficult to draw definite conclusions from available evidence. It is clear that there is currently little interest in sports sponsorship in the academic literature, despite the significant volume and value of sports sponsorship worldwide. This therefore constitutes an important gap in the literature, i.e. studies evaluating the use of sports sponsorship in social marketing and public health are urgently needed. While it is important to acknowledge that in practice sponsorship is often one of several elements of the marketing mix, there are studies identifying sponsorship as one of the strategies used in public health and social marketing campaigns, and any identified and reported behavioural impacts are an outcome of the total marketing mix. Yet there is a conspicuous lack of more detailed description and evaluations of sponsorship effectiveness, and future studies should compare impacts where sponsorship is the primary or only tool versus campaigns where sponsorship is part of a comprehensive marketing mix to examine the role that sponsorship plays in overall program effectiveness. 
Previous studies indicated that health sponsorship is an Australian phenomenon where health promotion foundations act as sponsors (Crisp and Swerissen, 2003; Madill and O'Reilly, 2010). Our systematic review provides further evidence to support this claim as fifteen out of seventeen studies were about Australian sponsorships. Ten of them focused on evaluations of two large health sponsorship programmes run by two state health promotion agencies Western Australia's Healthway and Victoria's VicHealth. Four additional studies focused on specific campaigns associated with VicHealth and Healthway's sponsorship programmes. We can therefore conclude that the majority of available evidence has come from Healthway and VicHealth. In consequence, as all studies reported on sponsorship programmes sponsored by state departments of health and their agencies, the health sponsorship landscape appears to be dominated by government funding. There is therefore a second significant gap in the literature - future studies are needed assessing the role, scope of involvement in, aims and benefits of non-government sponsors of public health and social marketing campaigns.

Sponsorship is typically one element of a much broader marketing mix. Therefore, evaluations of sponsorship need to be able to isolate the unique effect that one component (e.g. sponsorship) delivers within the wider mix. The overwhelming majority of studies identified in this review reported using surveys as the main evaluation method, which may limit understanding given known biases (Adamsen et al. 2013). Only three studies reported the use of methods that do not rely on self-report: sales data and observations. There is therefore a third significant gap in the literature - future studies using methods that extend beyond self-reporting, such as observations, are needed to gain a more accurate understanding of the effectiveness of health sponsorship on behavioural change. Additionally, methods exist permitting effects to be tested in isolation. For example, use of eye-tracking enables a team to assess whether messages placed in a venue attract target audience attention, 
which can provide a more direct assessment ensuring that any awareness and image reported is not reflecting the wider campaign.

Communication and structural change aims have been previously identified as the main aims of health sponsorship (Jalleh et al., 2002). However, Jalleh et al. (2002) emphasised it is unrealistic to expect that health sponsorship on its own and in a short period of time can have a direct effect on behaviour. In our systematic review, policy aim (structural change) was the main aim in two large sponsorship programmes run by Healthway and VicHealth. Only four studies reported behavioural aims. As expected, policy change outcomes were reported by ten studies, and ten studies also showed significant change in awareness. However, behavioural outcomes were reported in only three studies. Our results therefore confirm that health sponsorship can be effective in raising awareness and achieving policy aims, however there is very limited (albeit positive) evidence that health sponsorship can lead to change in attitudes, social norms and behaviours. However, in 1994 Andreasen stated that "the bottom line of social marketing is behaviour change" (p.111). Behaviour change can be found in all social marketing benchmark criteria classifications (Andreasen, 2002; French and Blair-Stevens, 2006; Walsh et al., 1993) as behaviour change is fundamental to evaluating campaign success. Social marketing scholars, French and Blair-Stevens (2006) stated that social marketing must have "a clear focus on behaviour, based on a strong behavioural analysis, with specific behaviour goals" (p.1). There is therefore the fourth gap in the literature - future studies are needed to explore the influence of sports sponsorship on attitudes, social norms and behaviours.

\section{Practical Implications}


All practical implications identified in this review must be viewed in light of the limited evidence currently available. (Limited) evidence exists indicating that smaller sponsorship values may be more effective in delivering changes than sponsorships of a larger value. For example, the evidence drawn from Holman et al. (1996) indicates that small sponsorship projects were more cost effective than larger sponsorship projects. Outcomes reported in the review suggest that practically leverage can be gained by providing smaller grants to more organisations to enhance outcomes.

Sponsorships requiring structural change delivered enhanced outcomes in comparison to sponsorships seeking communication and/or policy only change. The introduction of practices in Surf Lifesaving Victoria Association for lifesavers delivered long-term outcomes and sustained change at a national level over time (see Dobbinson et al., 1999). In order to best leverage sponsorship it is recommended that sponsorship agreements seek practice change as the key deliverable rather than communication or policy aims.

\section{Conclusions, Limitations and Future Research Directions}

This paper provided a systematic review of evaluations of public health and social marketing campaigns reporting the use of sports sponsorship. Although seventeen peer-reviewed studies reporting evaluations of sports sponsorship programs and campaigns in social marketing and public health were identified, only one study has been published in the last 10 years, confirming that sponsorship literature is largely conceptual in nature (Madill et al., 2014). This research contributes to our knowledge of the actual and potential impact of sports sponsorship in social marketing and health promotion in two main areas. First, the systematic literature review reported in this paper provides an overview of the current state of play by systematically reviewing and synthetising a large amount of information included in all 
identified studies to provide insights into some of the key aspects of sponsorship campaigns, including locations, target audiences, aims, evaluation methods and outcomes. The results indicate that sport sponsorship can be very effective in influencing policy and raising awareness. However, there is only limited positive evidence that sport sponsorship can be used to facilitate positive behavioural change. Second, the insights were used to identify four gaps in the literature and recommend future research areas in sports sponsorship in social marketing in public health. The four areas included the need for studies empirically evaluating the use of sponsorship in social marketing and public health campaigns, studies assessing the role, scope of involvement in, aims and benefits of non-government sponsors of public health and social marketing campaigns, studies that do not rely on self-reporting, and studies measuring the impact of sports sponsorship on attitudes, social norms and behaviours. This review has important limitations. First, analysis presented in this review included information that was reported in the identified studies, which might be an incomplete representation of work undertaken but not reported. Many of the excluded studies did not report details of their sponsorship programmes or evaluations of those programmes. Social marketing and public health studies tend to report campaign outcomes rather than the process through which such outcomes are achieved. It is therefore important for researchers when presenting the outcomes of their campaign to describe the campaigns and report their results in a comprehensive manner to enable future systematic reviews of evidence. Second, all of the studies identified in this review were conducted in English speaking countries. Future reviews should be conducted in other languages to review studies and campaigns which might have not been published in English. 


\section{References}

Adamsen, J.M., Rundle-Thiele, S. and Whitty, J.A. (2013), "Best-Worst scaling...reflections on presentation, analysis, and lessons learnt from case 3 BWS experiments", Market \& Social Research, Vol. 21 No. 1, pp. 9-27.

Babor, T., Caetano, R., Casswell, S. et al. (2010), Alcohol. No ordinary commodity. Research and public policy, Oxford University Press, Oxford.

Carins, J.E. and Rundle-Thiele, S.R. (2014), "Eating for the better: A social marketing review (2000-2012)", Public Health Nutrition, Vol. 17, pp. 1628-1639.

Corti, B., Donovan, R.J., Holman, C.A.J., Coten, N. and Jones, S.J. (1997), "Using sponsorship to promote health messages to children" Health Education \& Behavior, Vol. 24 No. 3, pp. 276-286.

Corti, B., Holman, C.A.J., Donovan, R.J., Frizzell, S.K. and Carroll, A.M. (1995), "Using sponsorship to create healthy environments for sport, racing and arts venues in Western Australia", Health Promotion International, Vol. 10 No. 3, pp. 185-197.

Corti, B., Holman, C.A.J., Donovan, R.J., Frizzell, S.K., and Carroll, A.M. (1997a), "Warning: attending a sport, racing or arts venue may be beneficial to your health", Australian and New Zealand Journal of Public Health, Vol. 21 No. 4, pp. 371-376.

Crisp, B.R. and Swerissen, H. (2003), "Critical processes for creating health-promoting sporting environments in Australia", Health Promotion International, Vol. 18 No. 2, pp. $145-152$.

Cuijpers, P. (2002), "Effective ingredients of school-based drug prevention programs: a systematic review", Addictive Behaviors, Vol. 27 No. 6, pp. 1009-1023. 
Dobbinson, S., Borland, R. and Anderson, M. (1999), "Sponsorship and sun protection practices in lifesavers", Health Promotion International, Vol. 14 No. 2, pp. 167-176.

Dobbinson, S.J., Hayman, J.A. and Livingston, P.M. (2006), "Prevalence of health promotion policies in sports clubs in Victoria, Australia", Health Promotion International, Vol. 21 No. 2, pp. 121-129.

Donovan, R.J. and Henley, N. (2010), Principles and practice of social marketing: an international perspective, Cambridge University Press.

Donovan, R.J., Holman, C.A.J., Corti, B. and Jalleh, G. (1997), “Evaluating sponsorship effectiveness: An epidemiological approach to analysing survey data", Australiasian Journal of Marketing Research, Vol. 5 No. 2, pp. 9-23.

Giles-Corti, B., Clarkson, J.P., Donovan, R.J., Frizzell, S.K., Carroll, A.M., Pikora, T. and Jalleh, G. (2001), "Creating smoke-free environments in recreational settings", Health Education \& Behavior, Vol. 28 No. 3, pp. 341-351.

Hastings, G.B., Macaskill, S., McNeill, R.E. and Leathar, D.S. (1988), "Sports sponsorship in health education", Health Promotion International, Vol. 3 No. 2, pp. 161-169.

Holman, C.A.J., Donovan, R.J. and Corti, B. (1993), "Evaluating projects funded by the Western Australian Health Promotion Foundation: a systematic approach", Health Promotion International, Vol. 8 No. 3, pp. 199-208.

Holman, C.A.J., Donovan, R.J., Corto, B., Jalleh, G., Frizzell, S.K. and Carroll, A.M. (1996), "Evaluating projects funded by the Western Australian Health Promotion Foundation: first results", Health Promotion International, Vol. 11 No. 2, pp. 75-88.

Holman, C.D., Donovan, R.J., Corti, B., Jalleh, G., Frizzell, S.K. and Carroll, A.M. (1997), "Banning tobacco sponsorship: replacing tobacco with health messages and creating health-promoting environments", Tobacco Control, Vol. 6 No. 2, pp. 115-121. 
Ivers, R.G., Castro, A., Parfitt, D., Bailie, R.S., D'Abbs, P.H. and Richmond, R.L. (2006), "Evaluation of a multi-component community tobacco intervention in three remote Australian Aboriginal communities", Australian and New Zealand Journal of Public Health, Vol. 30 No. 2, pp. 132-136.

Jalleh, G., Donovan, R.J., Clarkson, J., Marhc, K., Foster, M. and Giles-Corti, B. (2001), "Increasing mouthguards usage among junior rugby and basketball players", Australian and New Zealand Journal of Public Health. Vol. 25 No. 3, pp. 250-252.

Jalleh, G., Donovan, R.J., Giles-Corti, B. and Holman, C.A.J. (2002), “Sponsorship: impact on brand awareness and brand attitudes", Social Marketing Quarterly, Vol. 8 No. 1, pp. $35-45$.

Kubacki, K., Rundle-Thiele, S., Pang, B. and Buyucek, N. (2015), "Minimising alcohol harm: a systematic social marketing review (2000-2014)", Journal of Business Research, Vol. 68 No.10, pp. 2214-2222.

Madill, J. and O'Reilly, N. (2010), “Investigating social marketing sponsorships: terminology, stakeholders, and objectives", Journal of Business Research, Vol. 63 No. 2, pp. 133-139.

Madill, J., O'Reilly, N. and Nadeau, J. (2014), “Financing social marketing programs through sponsorship: implications for evaluation”, Journal of Social Marketing, Vol. 4 No.1, pp.22-37.

Meenaghan, T. (1983), “Commercial sponsorship,” European Journal of Marketing, Vol. 7 No. 7, pp. 5-73.

National Health and Medical Research Council (NHMRC) (1996), Health-promoting sports, arts and racing settings: New challenges for the health sector, Australian Government Publishing Service, Canberra. 
Oddy, W.H., Holman, C.D.A.J., Corti, B. and Donovan, R.J. (1995), "Epidemiological measures of participation in community health promotion projects", International Journal of Epidemiology, Vol. 24 No. 5, pp. 1013-1021.

Olsen C.K. (1999), “Countering pro-tobacco influences at the racetrack”, American Journal of Public Health, Vol. 89 No. 9, pp. 1431-1432.

O'Reilly, N.J. and Madill, J.J. (2007), “Evaluating social marketing elements in sponsorship”, Social Marketing Quarterly, Vol. 13 No. 4, pp. 1-25.

Rifon, N.J., Choi, S.M., Trimble, C.S. and Li, H. (2004), “Congruence effects in sponsorship: the mediating role of sponsor credibility and consumer attributions of sponsor motive", Journal of Advertising, Vol. 33 No. 1, pp. 29-42.

Rodgers, S. and Bae. J. (2007), "Stigmatizing effects of pro social alcohol and tobacco esponsorships”, Social Marketing Quarterly, Vol. 13 No. 1, pp. 15-30.

Rosenberg, M. and Ferguson, R. (2014), "Maintaining relevance: an evaluation of health message sponsorship at Australian community sport and arts events", BMC Public Health, Vol. 14 No. 1, pp. 1.

Weinreich, N.K., Abbott, J. and Olson, C.K. (1999), "Social marketers in the driver's seat: Motorsport sponsorship as a vehicle for tobacco prevention", Social Marketing Quarterly, Vol. 5 No. 3, pp. 108-112. 